Tropical Journal of Pharmaceutical Research December 2014; 13 (12): 2091-2099

ISSN: $1596-5996$ (print); 1596-9827 (electronic)

(C) Pharmacotherapy Group, Faculty of Pharmacy, University of Benin, Benin City, 300001 Nigeria.

All rights reserved.

Available online at http://www.tjpr.org

Original Research Article

http://dx.doi.org/10.4314/tjpr.v13i12.21

\title{
Antibiotic Resistance Pattern and Molecular Epidemiology of Methicillin-Resistant Staphylococcus aureus Colonization in Burns Unit of a Tertiary Care Hospital in Peshawar, Pakistan
}

\author{
Bashir Ahmad", Farmanullah Khan ${ }^{1,2}$, Jawad Ahmed ${ }^{3}$, Seung Bin Cha ${ }^{2}$, Min- \\ Kyoung Shin ${ }^{3}$, Shumaila Bashir ${ }^{4}$ and Han Sang Yoo ${ }^{2 *}$ \\ ${ }^{1}$ Center of Biotechnology and Microbiology, University of Peshawar, Pakistan, ${ }^{2}$ Departments of Infectious Disease, College of \\ Veterinary Medicine, Seoul National University 151-742, Korea, ${ }^{3}$ Institute of Basic Medical Sciences, Khyber Medical University, \\ ${ }^{4}$ Department of Pharmacy, University of Peshawar, Peshawar, Pakistan
}

*For correspondence: Email: yoohs@snu.ac.kr; Tel: +82 2 8801263; Fax: +82 28742738

\begin{abstract}
Purpose: To develop strategies for the control of hospital-acquired methicillin-resistant Staphylococcus aureus (HA-MRSA) which is a serious threat to burns patients with the aid of molecular studies. Methods: Staphylococcus aureus strains were collected from the Burns Unit of Khyber Teaching Hospital (KTH) Peshawar, Pakistan from July - December 2011. Antibiotic resistance was determined according to the recommendations of Clinical Laboratory Standard Institute (CLSI). Molecular epidemiology of the S. aureus strains were determined by pulse field gel electrophoresis (PFGE).

Results: PFGE identified 14 clusters which included 29 different pulso-types prevailing in the Burns Unit. Of the 29 types, 11 contained two or more strains of the same pulso-type. These MRSA isolates were highly resistant to various kinds of penicillin and cephalosporin (85-100\%). Among the important anti-staphylococal agents tested, $17 \%$ of the isolates were resistant to fusidic acid and linezolid. All the 54 strains were susceptible to vancomycin.

Conclusion: Several of the same pulso-types prevail in the Burns Unit of KTH. Furthermore, 29 pulsotypes among the 54 strains suggest the diversity of the MRSA strains collected from burns patients.
\end{abstract}

Keywords: Epidemiology, Pulso-type, Fusidic acid, Linezolid, Vancomycin, Methicillin-resistant Staphylococcus aureus, Burns

Tropical Journal of Pharmaceutical Research is indexed by Science Citation Index (SciSearch), Scopus, International Pharmaceutical Abstract, Chemical Abstracts, Embase, Index Copernicus, EBSCO, African Index Medicus, JournalSeek, Journal Citation Reports/Science Edition, Directory of Open Access Journals (DOAJ), African Journal Online, Bioline International, Open-J-Gate and Pharmacy Abstracts

\section{INTRODUCTION}

Patients with burns injuries are more prone to microbial colonization due to disruption of the skin thereby providing a favorable environment to microorganisms from the normal flora of patients, healthcare personnel and the hospital environment [1]. Burns patients with an impaired immune system can acquire methicillin-resistant Staphylococcus aureus (MRSA) which is one of the most focused pathogens worldwide. It has been observed in many cases that the same types of hospital acquired (HA)-MRSA are responsible for the outbreaks [2]. As a result infections caused by these multidrug resistant MRSA strains are difficult and costly to treat [3]. The routes of transmission and causes of MRSA infections in burn units include patients susceptibility, surgical procedures, health care worker who are carrier for MRSA, the ability of $S$. 
aureus to survive on surfaces and airborne dissemination [4,5]. The previous stay of MRSApositive patients in a room and objects used for such patients are also causes of transmission if the room is not disinfected properly [6].

The frequency of healthcare-associated infections caused by MRSA in Khyber Pukunkhwa Province of Pakistan has not been well evaluated and the data available are limited. However, studies conducted recently in the whole country suggested that 42 - $51 \%$ of healthcare-associated $S$. aureus infections may be caused by MRSA [7]. Multidrug resistant MRSA has also been reported in other hospitals in the same province [8] with high level of resistance to beta lactam antibiotics. Likewise, studies reported from India exhibited 51.6 - 54.9 $\%$ incidence of MRSA infections [9].

The severe threat to the patients in hospital settings due to MRSA highlights the importance of conducting an epidemiological investigation of the outbreaks in order to overcome their propagation [10]. Pulse field gel electrophoresis (PFGE) is considered the gold standard technique for the study of the epidemiology of bacterial strains in hospital settings [11]. Therefore, this technique was used to investigate the molecular epidemiology of MRSA isolated from burns patients in Khyber Teaching Hospital, Peshawar, Pakistan which is a tertiary care hospital). The purpose of this study was to determine the clonal similarities of MRSA strains found in the burns unit, and are transmitted from patient to patient by various means. The results of this study might be useful for the development of strategies and adaptation of guidelines [12] that may help to overcome HA-MRSA infections in burn patients.

\section{EXPERIMENTAL}

The MRSA strains were collected from burn patients in Khyber Teaching Hospital Peshawar, Pakistan (July - December 2011). These patients were admitted to the Burns Ward (BW) comprised of 10 beds for patients older than 12 years of age and Pediatrics Surgical Ward (PSW) consisting 8 beds for children. The beds which were allocated for male and children were not surrounded by curtains to isolate them; however, the beds of female patients were surrounded by curtains. Hygienic conditions were not satisfactory and air filtration system was inadequate to clean up the air circulating in the burn units.

\section{Isolation and identification of MRSA strains}

A total of 400 consecutive pus samples from the burn wounds were collected with sterile swab. These samples were screened and 90 S. aureus non-duplicate strains were isolated. The specimens were inoculated on blood agar and mannitol salt agar (MSA, Oxoid, UK), and the isolates were identified by colony morphology, gram staining, catalase, coagulase and DNase tests. These isolates were preserved in tryptone soya broth (TSB) with $15 \%$ glycerol at minus 40 oC for further studies.

Fifty-four positive MRSA isolates were collected from 21 female and 33 male patients after hospitalization $\geq 48 \mathrm{~h}$. Among these patients, children $\leq 12$ years numbered 25 out of 54 .

\section{Confirmation of methicillin-resistant Staphyl- ococcus aureus (MRSA)}

\section{Cefoxitin disc}

These strains were initially characterized as MRSA based on $30 \mu \mathrm{g}$ cefoxitin disc (Oxoid) susceptibility method recommended by Clinical Laboratory Standard Institute (CLSI) [13]. S. aureus ATCC 43300 and ATCC 25923 strains were used as positive and negative control respectively as recommended by CLSI.

\section{Brilliance MRSA-2 agar}

All 54 strains were refreshed in TSB , then inoculated on brilliance MRSA-2 agar (Oxoid), incubated over night at $37^{\circ} \mathrm{C}$ to confirm MRSA.

\section{Genetic confirmation of MRSA}

For DNA extraction, three to four colonies from overnight growth on Tryptone Soya Agar (TSA) were suspended in $25 \mu$ l of lysostaphin solution $(100 \mu \mathrm{g} / \mathrm{ml})$ [14] and incubated at $37^{\circ} \mathrm{C}$ for 10 min. Then, $25 \mu \mathrm{l}$ of proteinase $\mathrm{K}(100 \mu \mathrm{g} / \mathrm{ml})$ and $75 \mu$ of $0.1 \mathrm{M}$ Tris $\mathrm{HCl}(\mathrm{pH} 8.0)$ were added, and the mixture was incubated at $37{ }^{\circ} \mathrm{C}$ for a further $10 \mathrm{~min}$. The suspension was then heated at 97 ${ }^{\circ} \mathrm{C}$ for $5 \mathrm{~min}$.

The MRSA strains were genotypically confirmed by polymerase chain reaction (PCR) targeting the mecA gene responsible for methicillin resistance and a specific region of the 16s rDNA region of the $S$. aureus (nuc gene). A total of 20 $\mu l$ of reaction mixture was prepared for each PCR reaction. The reaction mixture was composed of $0.2 \mu \mathrm{l}$ Taq DNA polymerase (5

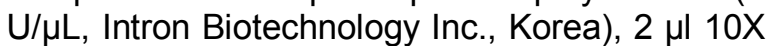
$\mathrm{PCR}$ reaction buffer (containing $100 \mathrm{mM}$ Tris- 
$\mathrm{HCL} \mathrm{pH}$ 8.3, $500 \mathrm{mM} \mathrm{KCl}, 20 \mathrm{mM} \mathrm{MgCl}), 2 \mu \mathrm{l}$ mixture of dNTPs (containing $2.5 \mathrm{mM}$ each dNTP) and $11.8 \mu$ l Nuclease-free water, $1 \mu$ l each of forward and reverse primers (15 pmoles) (Table 1), and $2 \mu \mathrm{l}$ of template DNA. PCR products were run in $1.5 \%$ agarose gel in $1 \mathrm{X}$ TAE buffer. The bands stained with ethidium bromide were examined under an ultraviolet transilluminator and photographed by a gel documentation system (Bio Rad Milan, Italy). ATCC 43300 and ATCC 25923 S. aureus strains were used as positive and negative control for the detection of mecA gene.

\section{Susceptibility test for antimicrobial agents}

Culture sensitivity data for 16 antibiotics were recorded (Table 2) according to the recommendation of the CLSI [13]. Minimum inhibitory concentrations (MICs) of Cefoxitin (FOX), Cephradine (CE), Ciprofloxacin (CIP), Vancommycin (VA), and Linezolid (LZD) were determined by the broth-micro dilution method as recommended.

The MIC of fusidic Acid was determined according to new criterion [15]. ATCC 43300 were used as a positive control for disc diffusion. ATCC 25923 and ATCC 29213 S. aureus strains were used as negative controls in disc diffusion and in the MIC tests respectively.

\section{PFGE method}

Isolates were refreshed on blood agar and a single colony was inoculated in $5 \mathrm{ml}$ TSB incubated overnight at $37{ }^{\circ} \mathrm{C}$. Plugs were prepared and subjected for cell lysis.

Plugs were digested with Smal restriction enzyme (Takara, Japan) and loaded into the wells of a $1 \%$ Sea Kem Gold agarose gel and run in 0.5 TBE using a CHEF- Mapper (Bio-Rad) according to the following parameters: $200 \mathrm{~V}(6$ $\mathrm{V} / \mathrm{cm}$ ), temperature $14{ }^{\circ} \mathrm{C}$, initial switch time $5 \mathrm{~s}$, final switch time $40 \mathrm{~s}$, with a total run time of 21 hours [16]. After the electrophoresis, the gel was stained in a $1.5 \mu \mathrm{g} / \mathrm{ml}$ Ethidium Bromide solution for $20 \mathrm{~min}$ in a covered container and destained in fresh distilled water for $45 \mathrm{~min}$. Lambda PFGE marker, 50-1000kb (cl857 ind 1 Sam7, NEW ENGLAND BioLabs) was used as a DNA ladder.

\section{Data processing and Analysis}

Gels images were taken by GEL DOC XR (Bio Rad Milan, Italy) and analyzed with BioNumerics software Gel Compar II (Applied Maths, Kortrijk, Belgium). Similarities in percentages were identified on a dendrogram derived from the unweighted pair group method using arithmetic averages based on Dice coefficients. Band position tolerance and optimization were set at 1.25 and $0.5 \%$, respectively. A similarity coefficient of $80 \%$ was selected to define the pulso-types clusters.

\section{RESULTS}

\section{Confirmation of MRSA}

The PCR products of the isolates were confirmed to be MRSA by expression of mecA and nuc gene. The blue colonies observed in Brilliance MRSA 2 agar also confirmed MRSA (Fig 1).

\section{Resistance pattern of antimicrobials}

None of the isolate was found susceptible or resistant to all of the antibiotics used against the 54 collected strains.

Among the beta-lactams tested, the MRSA strains were found $100 \%$ resistant to Cefoxitin, Ampicillin (Table 2), and Cephradine $\left(\mathrm{MIC}_{50}=\right.$ $128 \mu \mathrm{g} / \mathrm{ml}$; Table 3). Followed by Cefaclor, Ceftazidime and Cefexime $94 \%$ and Cefepime, Cefpirome and Amoxicillin + Clavulanic acid (Coamoxiclav) with a resistance rate of $85 \%$.

Table 1: PCR primer sequences, amplicon size and PCR conditions

\begin{tabular}{|c|c|c|c|c|}
\hline \multirow{2}{*}{ Gene } & \multirow{2}{*}{ Primer sequence $\left(5^{\prime}-3^{\prime}\right)$} & \multirow{2}{*}{$\begin{array}{l}\text { Product } \\
\text { size }\end{array}$} & \multicolumn{2}{|c|}{ PCR conditions } \\
\hline & & & $\begin{array}{l}\text { Annealing } \\
\text { temp. }\left({ }^{\circ} \mathrm{C}\right)\end{array}$ & Cycle \\
\hline $\operatorname{mec} A$ & $\begin{array}{l}\text { F-CTCAGGTACTGCTATCCACC } \\
\text { R-CACTTGGTATATCTTCACC }\end{array}$ & 449 & 55 & 30 \\
\hline Nuc & $\begin{array}{c}\text { F-GCGATTGATGGTGATACGGTT } \\
\text { R-AGCCAAGCCTTGACGAACTAAAGC }\end{array}$ & 280 & 55 & 30 \\
\hline
\end{tabular}




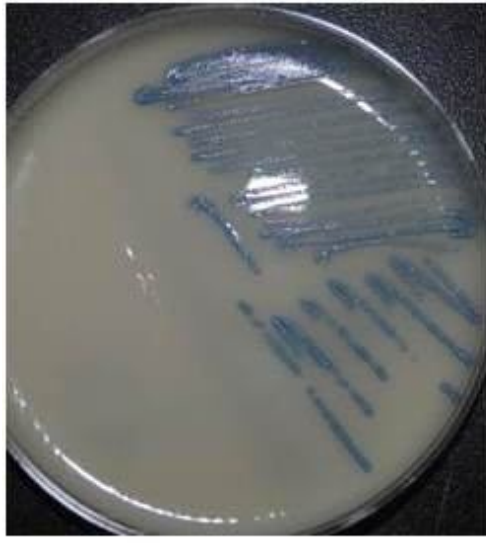

(a)



(b)

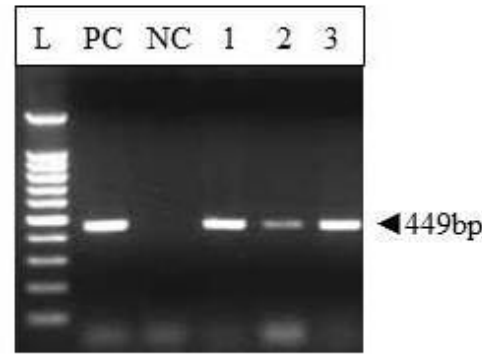

(c)

Fig 1: Confirmation of MRSA (a) Brilliance MRSA 2 agar: Blue color of the colonies on Brilliance MRSA 2 agar indicates growth of MRSA (b) Confirmation of $S$. aureus by detection of nuc gene (c) Confirmation of mec $A$ gene by PCR. Lane L: Molecular size marker (100bp), Lane PC: Positive control, Lane NC: Negative Control, 1-3: test samples

Resistance to meropenem was $50 \%$ which was much less than the other beta-lactams tested. Amikacin was very effective aminoglycoside with $37 \%$ isolates being sensitive to it followed by gentamicin with $30 \%$ activity. Excellent activity was observed with rifampicin with $94 \%$ of isolates being susceptible to it, followed by doxycycline (74\%), and chloramphenicol (56\%).

The macrolide, clarithromycin, had $41 \%$ activity, Trimethoprim+Sulphamethoxazole had $19 \%$ and the fluoroquinolone, ciprofloxacin had $17 \%$ activity $\left(\mathrm{MIC}_{50} \%=32 \mu \mathrm{g} / \mathrm{ml}\right.$ for ciprofloxacin tested using broth-micro dilution method).

Among the antistaphylococal agents tested against MRSA, using the broth-micro dilution method, $17 \%$ of the strains showed resistance to fusidic acid and linezolid. Intermediate resistance to Vancomycin was recorded in $28 \%$ of the isolates with MIC ranging from 4 to $8 \mu \mathrm{g} / \mathrm{ml}$ (Table 3).

Table 2: Antibiotic resistance pattern of MRSA isolates (illustrated in number and percent)

\begin{tabular}{|c|c|c|c|c|}
\hline Antibiotic/concentration & Symbol & $\begin{array}{c}\text { Resistant } \\
\quad N(\%) \\
\end{array}$ & $\begin{array}{c}\text { Intermediate } \\
N(\%) \\
\end{array}$ & $\begin{array}{c}\text { Susceptible } \\
(\%)\end{array}$ \\
\hline Cefoxitin /30 $\mu \mathrm{g}$ & FOX & $54(100)$ & $0(0)$ & $0(0)$ \\
\hline $\begin{array}{l}\text { Amoxicillin }+ \\
\text { Clavulanic acid } / 20+10 \mu \mathrm{g}\end{array}$ & AMC & $46(85)$ & $1(2)$ & $7(13)$ \\
\hline Ampicillin/10 $\mu \mathrm{g}$ & AMP & $54(100)$ & $0(0)$ & $0(0)$ \\
\hline Cefaclor/30 $\mu \mathrm{g}$ & CEC & $51(94)$ & $2(4)$ & $1(2)$ \\
\hline Ceftazdime/30 $\mu \mathrm{g}$ & CAZ & $51(94)$ & $1(2)$ & $2(4)$ \\
\hline Cefixime $/ 5 \mu \mathrm{g}$ & CFM & $51(94)$ & $0(0)$ & $3(6)$ \\
\hline $\begin{array}{l}\text { Cefepime } / 30 \mu \mathrm{g} \\
\text { Cefpirome } / 30 \mu \mathrm{g} \\
\text { Clarithromycin } / 15 \mu \mathrm{g} \\
\text { Meropenem } / 10 \mu \mathrm{g}\end{array}$ & $\begin{array}{l}\text { FEP } \\
\text { CPO } \\
\text { CLR } \\
\text { MEM }\end{array}$ & $\begin{array}{l}46(85) \\
46(85) \\
24(44) \\
27(50)\end{array}$ & $\begin{array}{c}4(7) \\
5(9) \\
8(15) \\
5(9)\end{array}$ & $\begin{array}{c}4(7) \\
3(6) \\
22(41) \\
22(41)\end{array}$ \\
\hline Gentamicin $/ 10 \mu \mathrm{g}$ & $\mathrm{CN}$ & $37(69)$ & $1(2)$ & $16(30)$ \\
\hline Amikacin $/ 30 \mu \mathrm{g}$ & AK & $25(46)$ & $9(17)$ & $20(37)$ \\
\hline Doxycycline/30 $\mu \mathrm{g}$ & DO & $6(11)$ & $8(15)$ & $40(74)$ \\
\hline $\begin{array}{l}\text { Trimethoprim+ } \\
\text { Sulphamethoxazole/25 } \mu \mathrm{g}\end{array}$ & SXT & $41(76)$ & $3(6)$ & $10(19)$ \\
\hline Rifampicin/5 $\mu \mathrm{g}$ & $\mathrm{RD}$ & $3(6)$ & $0(0)$ & $51(94)$ \\
\hline Chloramphenicol/30 $\mu \mathrm{g}$ & C & $21(39)$ & $3(6)$ & $30(56)$ \\
\hline
\end{tabular}


Table 3: Minimum inhibitory concentration of different antibiotics against MRSA isolates

\begin{tabular}{|c|c|c|c|c|c|c|c|c|c|c|c|c|c|c|c|c|}
\hline \multirow[b]{2}{*}{ Symbol } & \multicolumn{13}{|c|}{ Minimum Inhibitory Concentrations $(\mu \mathrm{g} / \mathrm{ml})$} & \multirow{2}{*}{$\begin{array}{l}\text { MIC } \\
50 \%\end{array}$} & \multirow{2}{*}{$\begin{array}{l}\text { MIC } \\
90 \%\end{array}$} & \multirow{2}{*}{$\begin{array}{c}\text { Total } \\
\text { samples }\end{array}$} \\
\hline & 0.125 & 0.25 & 0.5 & 1 & 2 & 4 & 8 & 16 & 32 & 64 & 128 & 256 & $>256$ & & & \\
\hline FOX & 0 & 0 & 0 & 0 & 0 & 0 & 0 & 1 & 5 & 10 & 16 & 14 & 8 & 128 & $>256$ & 54 \\
\hline $\mathrm{Ce}$ & 0 & 0 & 0 & 0 & 0 & 0 & 0 & 1 & 0 & 11 & 17 & 16 & 9 & 128 & $>256$ & 54 \\
\hline FD & 6 & 8 & 9 & 11 & 11 & 4 & 2 & 1 & 2 & 0 & 0 & 0 & 0 & 1 & 4 & 54 \\
\hline VA & 0 & 1 & 2 & 6 & 30 & 12 & 3 & 0 & 0 & 0 & 0 & 0 & 0 & 2 & 4 & 54 \\
\hline LZD & 0 & 0 & 0 & 7 & 19 & 19 & 6 & 2 & 1 & 0 & 0 & 0 & 0 & 4 & 8 & 54 \\
\hline CIP & 0 & 0 & 5 & 0 & 3 & 0 & 1 & 7 & 13 & 16 & 9 & 0 & 0 & 32 & 128 & 54 \\
\hline
\end{tabular}

Abbreviations: FOX, Cefoxitin; CE, Cephradine; FD, Fusidic acid; VA, Vancommycin; LZD, Linezolid; CIP, Ciprofloxacin

\section{Pulse field gel electrophoresis (PFGE)}

PFGE typing of MRSA strains characterized a polyclonal picture. The strains were classified into 14 pulsed-field type clusters from $\mathrm{A}$ to $\mathrm{N}$ which contains 29 different PFGE pulso-types, identified in the study period. Out of 29 pulsotypes or clones, 11 grouped two or more strains. The major clone found in the study is designated as C1aaba that grouped 9 isolates, followed by $\mathrm{C} 1 \mathrm{a} 4 \mathrm{~b}$ grouped $7, \mathrm{C} 1 \mathrm{~b}$ and $\mathrm{C} 2 \mathrm{a}$ grouped 3 isolates each while clone C1a5, D, E1aaa, E1aab, G1, H and 11 grouped 2 isolates each (Fig 2).

The name of the groups designated with more similar letters indicates that there exist a close relationship among the groups but calculated as different clones by software "Gel Compar II". The alphabetic grouping of clones shows the relatedness of strains.

Strains that were grouped in pulso-types C1aaba, C1a4b, C1a5, C1a3b and C1aabb are 20 in number. These groups are $94.8 \%$ similar as shown in the dendrogram (Fig 2).

Antibiotic susceptibility pattern of the same pulso-type strains is shown in Table 4. The results show that some similarities exist in the antibiotic susceptibility pattern of the same pulsotype strains, even though it is not uniform for all strains grouped in the same pulso-type. The minimum inhibitory concentration values were different for some strains that were grouped in the same pulso-type strains.

\section{DISCUSSION}

MRSA Infections are of growing concern in the burn units because of the immunosuppressed state of the patients. $S$. aureus can reside on the skin surface and nasal cavities of individuals, on inanimate objects (clothes and polyester objects) and transmitted through contaminated air leading to dissemination in patients [4].

We have observed poor hygienic environments in both the burn units for adults and children, which is in contrast to the guidelines adopted in the burn units worldwide [12]. Therefore, the occupancy and cross-transmission of MRSA clones occurs easily. In our study, we isolated the same clones from different patients who were admitted in both burn wards at different times. The 54 strains were classified in 14 clusters, designated from $\mathrm{A}$ to $\mathrm{N}$ according to published criteria [16]. Cluster $\mathrm{C}$ and cluster $\mathrm{E}$ have grouped 28 and 7 strains respectively. In these clusters, the groups and subgroups are in close relationship to each other due to the similarities in the band pattern of isolates. Pulso-type C1aaba, C1a4b have grouped 9, 7 isolates while $\mathrm{C} 1 \mathrm{~b}$ and $\mathrm{C} 2 \mathrm{a}$, have grouped 3 isolates each. Isolates grouped in every of the above mentioned pulso-type have the same band pattern which were the most abundant clones. A similar study conducted in Brazil showed that the same MRSA clones detected by PFGE were found in patients admitted at the same time to the same unit while the same clones were acquired by patients admitted later to the unit [17]. Another study observed that the same clone of MRSA was transmitted to a neonate from a mother identified by PFGE and subsequently cross-transmitted to other neonates admitted thereafter [10]. In addition to the detection of similar pulso-type MRSA clones in our study, we isolated other clones with distinguishable band patterns. A total of 29 pulso-types of 54 isolates were detected, which suggested that new strains are harbored from other sources, which is not surprising because of unhygienic environment in these units [5].

All MRSA isolates were multidrug drug resistant (MDR) as they showed resistance to more than three antibiotics used in our study. High level resistance to different penicillins such as $100 \%$ to ampicillin and $85 \%$ amoxicillin + clavulanic 


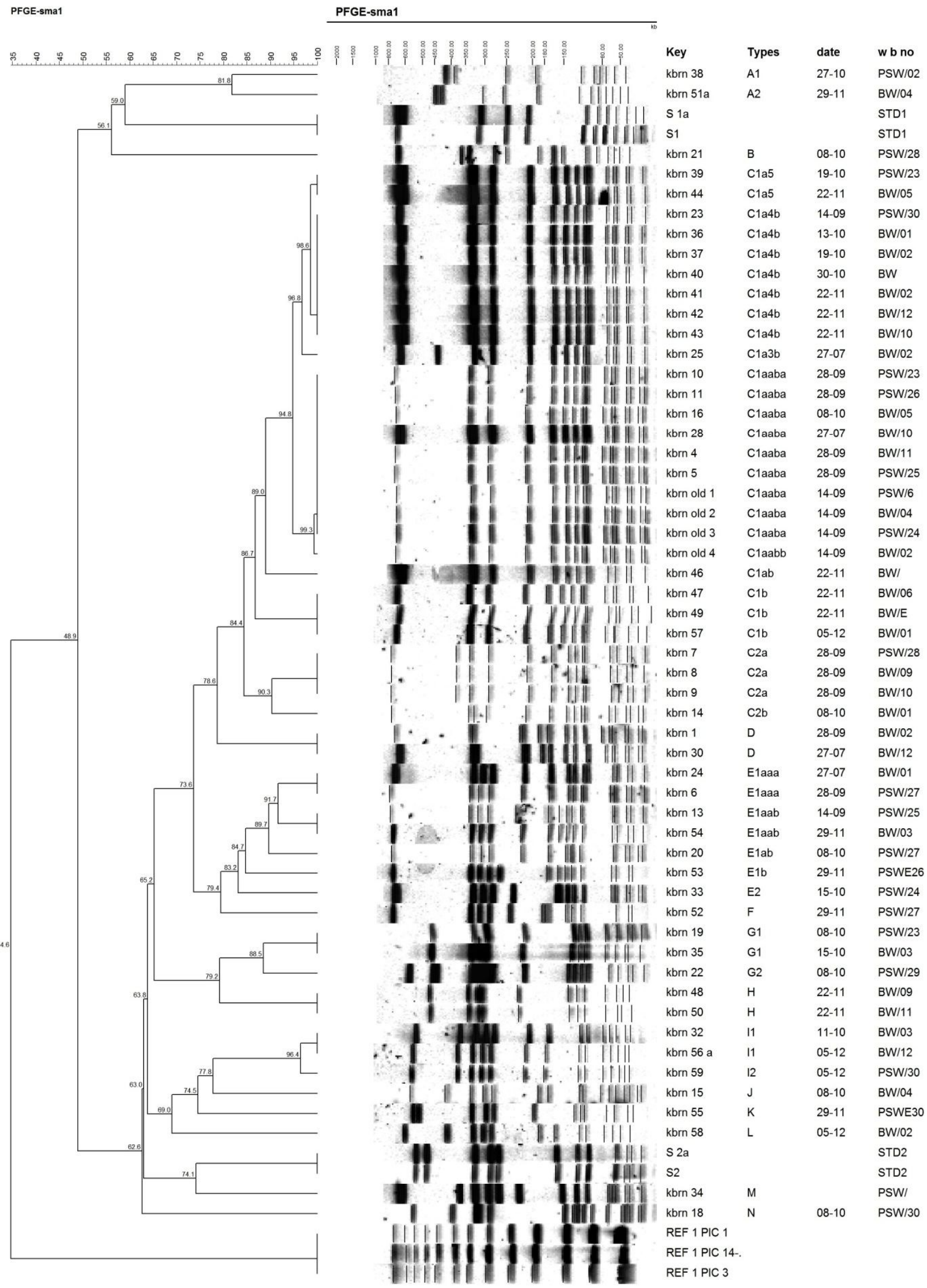

Fig 2: Dendrogram of MRSA Isolated from burn patients. Key: Strain number, date (day-month- 2011) W b no: ward and bed number (BW: Burn Ward, PSW: Pediatric Surgical Ward). S1 and S1a: ATCC 43300, S2 and S2a: ATCC 29213. REF: Lambda Ladder 50-1000kb in different gels was used 
Table 4: Antimicrobial resistance of related PFGE types strains

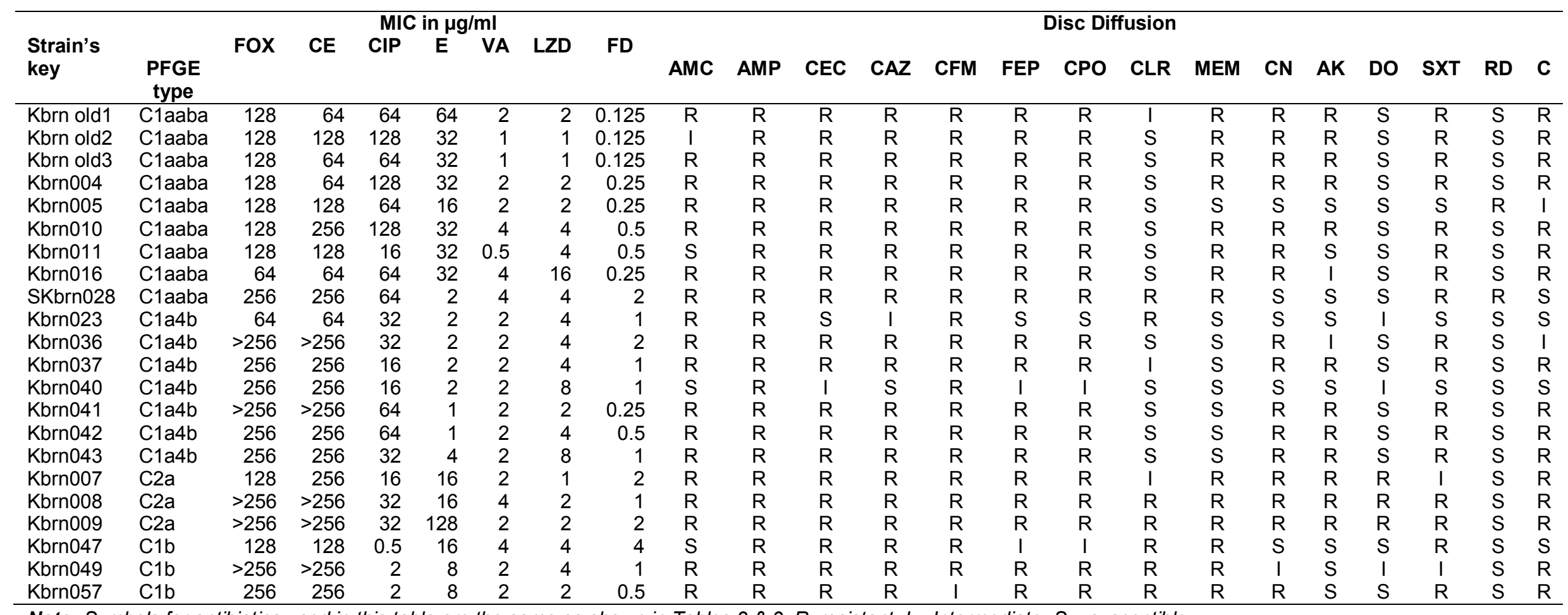

Note: Symbols for antibiotics used in this table are the same as shown in Tables 2 \& 3. R: resistant; I = Intermediate; $S=$ susceptible 
acid (co-amoxiclav) was observed. Among different cephalosporins, we observed $100 \%$ resistance to cephradine, (94\%) to cefaclor, ceftazidime, cefexime and $85 \%$ resistance to cefepime and cefpirome. However, the resistance to meropenem, a potent beta lactam was $50 \%$. Similarly high level of resistance among MRSA strains were reported in an early multi-center study from Pakistan which showed $100 \%$ resistance to oxacillin, penicillin, ampicillin and $92.4 \%$ resistance to cephalothin while resistance to meropenem was $40 \%$ [8].

In the present study, amikacin showed $37 \%$ activity followed by gentamicin with $30 \%$ activity. However different studies conducted in Pakistan reported varying data, e.g., a study reported 50 $\%$ and $0 \%$ susceptibility for amikacin and gentamycin respectively in one city [18] whereas it was reported to be $21 \%$ and $16 \%$ for amikacin and gentamycin respectively in the other [19]. These differences may be due to the differences in prescription pattern that have resulted different resistance patterns in MRSA prevailing in different parts of Pakistan.

In the present study, among the antistphylococal agents tested against MRSA by the broth microdilution method, $17 \%$ of the strains were resistant to fusidic acid which correlates with the study reported from Agha Khan University Hospital in Karachi showing $18 \%$ resistance for fusidic acid [7]. The observed $17 \%$ resistance to Linezolid is much higher than previously reported [20]. There was no vancomycin resistant strain isolated in this study or by other researchers in this region $[7,8,18]$.

\section{CONCLUSION}

The prevalence of the same pulso-type strains (i.e., the same clones) were commonly found in two burn units of KTH, Peshawar Pakistan. Several outbreaks identified in this study suggest that MRSA strains easily transmit to the newly admitted patients in the same ward. Therefore care should be taken to reduce the route of MRSA transmission, which would reduce the rate of morbidity and mortality among burn patients. The applications of adequate cleaning procedures and adoption of standard operating procedures, (12), are recommended to overcome infection outbreaks. This should also bring about the reduction of cost of medication and length of hospitalization required.

\section{ACKNOWLEDGEMENT}

The study was sponsored and supported by The Higher Education Commission of Pakistan, under the International Research Support Initiative Program (IRSIP), the Kohat University of Science and Technology (KUST) and The Research Institute for Veterinary Science, Seoul National University, Seoul Korea. We are thankful to Dr. Sun Young Hwang and Mr. Jung Yeon Soo for their guidance in the use of BioNumerics software Gel Compar II.

\section{REFERENCES}

1. Church D, Elsayed S, Reid O, Winston B, Lindsay $R$. Burn wound infections. Clin Microbiol Rev 2006; 19(2): 403-434.

2. Fluit AC, Wielders CLC, Verhoef J, Schmitz FJ. Epidemiology and susceptibility of 3,051 Staphylococcus aureus isolates from 25 university hospitals participating in the European SENTRY study. J Clin Microbiol 2001; 39(10): 3727-3732.

3. Rubin RJ, Harrington CA, Poon A, Dietrich K, Greene JA, Moiduddin $A$. The economic impact of Staphylococcus aureus infection in New York City hospitals. Emerg Infect Dis 1999; 5(1): 9-17.

4. Kaiser ML, Thompson DJ, Malinoski D, Lane C, Cinat ME. Epidemiology and risk factors for hospitalacquired methicillin-resistant Staphylococcus aureus among burn patients. J Burn Care Res 2011; 32(3): 429-434.

5. Gehanno JF, Louvel A, Nouvellon M, Caillard JF, PestelCaron M. Aerial dispersal of methicillin-resistant Staphylococcus aureus in hospital rooms by infected or colonised patients. J Hosp Infect 2009; 71(3): 256262.

6. Otter JA, Yezli S, French GL. The role played by contaminated surfaces in the transmission of nosocomial pathogens. Infect Control Hosp 2011; 32(7): 687-699.

7. Zafar A, Stone M, Ibrahim S, Parveen Z, Hasan Z, Khan E, Hasan R, Wain J, Bamford K. Prevalent genotypes of methicillin-resistant Staphylococcus aureus: report from Pakistan. J Med Microbiol 2011; 60(1): 56-62.

8. Naeem M, Adil M, Naz SM, Abbas SH, Khan A, Khan MU. Resistance and sensitivity pattern of Staphylococcus aureus; A study in Lady Reading Hospital Peshawar. J Postgrad Med Inst 2013; 27(1): 42-47.

9. Anupurba S, Sen MR, Nath G, Sharma BM, Gulati AK, Mohapatra TM. Prevalence of methicillin resistant Staphylococcus aureus in a Tertiary Referral Hospital in Eastern Uttar, Pradesh. Indian J Med Microbiol 2003; 21(1): 49-51.

10. Morel A-S, Wu F, Della-Latta P, Cronquist A, Rubenstein $D$, Saiman $L$. Nosocomial transmission of methicillinresistant Staphylococcus aureus from a mother to her

Trop J Pharm Res, December 2014; 13(12): 2098 
preterm quadruplet infants. Am J Infect Control 2002; 30(3): 170-173.

11. Tenover FC, Arbeit RD, Goering RV, Mickelsen $P A$, Murray $B E$, Persing $D H$, Swaminathan B. Interpreting chromosomal DNA restriction patterns produced by pulsed-field gel electrophoresis: criteria for bacterial strain typing. J Clin Microbiol 1995; 33(9): 2233-2239.

12. Rafla $K$, Tredget EE. Infection control in the burn unit. Burns 2011; 37(1): 5-15.

13. Wayne PA: Clinical and Laboratory Standards Institute (CLSI). Performance Standards for Antimicrobial Susceptibility Testing: Twenty-first Informational Supplement M100-S21. 2011.

14. Kumari DN, Keer V, Hawkey PM, Parnell P, Joseph N, Richardson JF, Cookson B. Comparison and application of ribosome spacer DNA amplicon polymorphisms and pulsed-field gel electrophoresis for differentiation of Methicillin-Resistant Staphylococcus aureus strains. J Clin Microbiol 1997; 35(4): 881-885.

15. Jones RN, Castanheira $M$, Rhomberg $P R$, Woosley $L N$, Pfaller MA. Performance of fusidic acid (CEM-102) susceptibility testing reagents: broth microdilution, disk diffusion, and Etest methods as applied to
Staphylococcus aureus. J Clin Microbiol 2010; 48(3): 972-976

16. McDougal LK, Steward CD, Killgore GE, Chaitram JM, McAllister SK, Tenover FC. Pulsed-field gel electrophoresis typing of oxacillin-resistant Staphylococcus aureus isolates from the United States: establishing a national database. J Clin Microbiol 2003; 41(11): 5113-5120.

17. Rodrigues MVP, Fortaleza CMCB, Riboli DFM, Rocha RS, Rocha C, Cunha MdLRd. Molecular epidemiology of methicillin-resistant Staphylococcus aureus in a burn unit from Brazil. Burns 2013; 39(6): 1242-1249

18. Iqbal K, Khan MI, Satti L. Microbiology of chronic suppurative otitis media: Experience at Dera Ismail Khan. Gomal J Med Sci 2011; 9(2): 189-193

19. Perwaiz S, Barakzi Q, Farooqi BJ, Khursheed N, Sabir N. Antimicrobial susceptibility pattern of clinical isolates of methicillin resistant Staphylococcus aureus. J Pak Med Assoc 2007; 57(1): 2-4.

20. Tsiodras S, Gold HS, Sakoulas G, Eliopoulos GM, Wennersten C, Venkataraman L, Moellering RC, Ferraro MJ. Linezolid resistance in a clinical isolate of Staphylococcus aureus. Lancet 2001; 358(9277): 207-208. 